\title{
The Effects of Imagery Interventions in Sports: A Meta-Analysis
}

Bianca A. Simonsmeier ${ }^{\mathrm{a}}$, Melina Andronie ${ }^{\mathrm{a}}$, Susanne Buecker ${ }^{\mathrm{b}}$, \& Cornelia Frank ${ }^{\mathrm{c}}$

${ }^{a}$ Educational Psychology, University of Trier, Trier, Germany

${ }^{b}$ Department of Psychology, Ruhr-University Bochum, Bochum, Germany

${ }^{c}$ Neurocognition and Action, University of Bielefeld, Bielefeld, Germany

This is a preprint version of a manuscript that has not yet been peer reviewed for formal publication. It might be published in a different version in the future. Supplemental Materials are provided via the Open Science Framework: https://osf.io/bxyjw/?view only $=5 \mathrm{a} 4 \mathrm{c} 703855 \mathrm{~b} 84 \mathrm{be} 3 \mathrm{a} 1264 \mathrm{cb} 4 \mathrm{~cd} 62 \mathrm{eef} 2$

Version: April 2020

If you want to cite this work, please use the following citation:

Simonsmeier, B. A., Andronie, M., Buecker, S., \& Frank, C. (2020). The Effects of Imagery Interventions in Sports: A Meta-Analysis. Manuscript submitted for publication.

Please contact the corresponding author (simonsm@uni-trier.de) to make sure you are using the latest version of this preprint. 


\begin{abstract}
Imagery interventions are an established psychological tool to enhance performance, psychological skills, and injury rehabilitation. Previous meta-analyses found positive effects of mental practice on performance, leaving it open whether imagery can also enhance other outcomes than performance such as motivational or affective outcomes. We performed a meta-analysis to extend the current understanding of the effectiveness of imagery in sports on any sport specific outcome and the relevance of third variables potentially moderating the effect. The overall effect of imagery interventions was medium in magnitude with $d=0.431$ (95\% CI [0.298, 0.563]). Imagery interventions significantly enhanced motor performance, motivational outcomes, and affective outcomes. Imagery combined with physical practice was more effective than physical practice alone, indicating differential effects of imagery and physical practice. The effectiveness of imagery was positively associated with the intensity of the imagery training. We discuss our results against previous and most recent meta-analyses on mental practice and the background of theoretical and practical aspects of imagery. Moreover, we lay out directions for future research by providing a comprehensive overview of research gaps in the literature on imagery. Keywords: imagery; interventions; mental practice; mental strategies; mental stimulation; review
\end{abstract}




\section{The Effects of Imagery Interventions in Sports: A Meta-Analysis}

Imagery is one of the most popular and well-accepted sport psychological strategies to improve performance, psychological skills, and injury rehabilitation (e.g., Cumming \& Ramsey, 2009; Cumming \& Williams, 2013; Guillot \& Collet, 2008). It describes "the creation and re-creation of an experience generated from memorial information, involving quasi-sensorial, quasi-perceptual, and quasi-affective characteristics, that is under the volitional control of the imager, and which may occur in the absence of the real stimulus antecedents normally associated with the actual experience“ (Morris, Spittle, \& Watt, 2005, p. 19). Sometimes, imagery and mental practice are used synonymously. The constructs are comparable in terms of describing a cognitive process of symbolic rehearsal. However, mental practice does not necessarily involve imagery but can also refer to other types of mental processes or mental preparation including self-talk or relaxation. To be distinguished from that imagery is a specific mental process that can be mentally practiced (Murphy \& Martin, 2002) and that includes the creation and re-creation of an experience of any kind not limited to motor performance. The present meta-analysis has the aim to extend the current understanding of the effectiveness of imagery interventions by investigating the effectiveness of different types of imagery on various outcomes, employing comprehensive analyses regarding control conditions and comparisons, and using state-of-the-art meta-analytic strategies.

Previous meta-analyses summarized the great amount of single studies on the effectiveness of mental practice and indicated positive effects on motor performance. Table 1 provides an overview of the main characteristics of the previous meta-analyses regarding conceptual and methodological aspects. The two earliest published meta-analyses (Feltz \& Landers, 1983; Hinshaw, 1991) investigated the effectiveness of interventions that included both mental practice and mental preparation (e.g., imagery, self-talk, relaxation). While these meta-analyses provided first evidence on the effectiveness of mental practice on performance, 
conclusions about the effectiveness of mental practice as an individual strategy cannot be drawn. This limitation was addressed in a later meta-analysis that included studies employing mental practice interventions only (Driskell, Copper, \& Moran, 1994). The analysis revealed a medium positive effect of mental practice on performance when compared to no-treatment control conditions with $d=0.527$ comprising 62 effect sizes from 35 studies. Toth, McNeill, Hayes, Moran, and Campbell (2020) currently performed a methodological replication of the Driskell et al. (1994) study including 37 studies and 99 effect sizes from research of the past 25 years. They also found a positive effect comparable in magnitude of $d=0.419$ which was, however, substantially lower when accounting for publication bias $(d=.264)$. Besides demonstrating the effectiveness of mental practice to enhance performance, the two metaanalysis further provide valuable insights in relevant third variables moderating the effect leading to relevant practical implications. For example, both meta-analyses highlight the relevance of the duration of the mental practice session. Results indicated an inverse (Driskell et al., 1994) and inverse U-shaped relationship (Toth et al., 2020) suggesting 20 minute sessions to be most effective.

\section{Limitations and Extensions of Previous Meta-Analyses on Mental Practice}

Previous meta-analyses provide valuable theoretical and practical insights on the effectiveness of mental practice on performance, but do not provide an integration of the comprehensive existing literature on imagery training thus far. Specifically, the present analysis aims at extending results of previous meta-analyses in three ways: by implementing different inclusion criteria, including other potential moderating variables, and applying stateof the art statistical method which will be discussed in the following.

First, all previous meta-analyses provide evidence for the effectiveness of mental practice to enhance performance. It is however suggested that imagery is effective to enhance a variety of outcomes such as psychological skills and not only performance as indicated in different models on imagery (Cumming \& Williams, 2013; Guillot \& Collet, 2008; Martin, Moritz, \& 
Hall, 1999). This has also been considered in single studies that, for example, investigated the effectieness of imagery on other outcomes such as anxiety or self-confidence (e.g., Callow, Hardy, \& Hall, 2001; Hale \& Whitehouse, 1998; Hammond, Gregg, Hrycaiko, Mactavish, \& Leslie-Toogood, 2012). It is desriable to evaluate the effectiveness of imagery on outcomes other than performance (Wakefield \& Smith, 2012) to obtain an overall picture of the effectiveness of imagery interventions in sport. As the previous meta-analyses did not consider other outcomes than performance, it is still unclear if the effect of imagery exists for other outcomes as well. To estimate the overall effectiveness of imagery, we included studies independent of the outcome assessed in the present meta-analysis. In our classification of outcomes, we followed models on imagery (Cumming \& Williams, 2013; Guillot \& Collet, 2008; Martin et al., 1999) and distinguish between performance outcomes, outcomes on strategies and problem solving, psychological outcomes including affective and motivational outcomes, rehabilitation outcomes, and psychological skills.

Second, imagery has emerged as a distinct research field within the domain of sport psychology and has significantly grown since which led to detailed theories on imagery (e.g., Cumming \& Williams, 2013; Guillot \& Collet, 2008; Holmes \& Collins, 2001; Martin et al., 1999). These models include many potential moderators, which have not been considered in the previous meta-analysis. For example, the Toth et al. (2020) meta-analysis included a moderator analysis considering imagery modality, namely visual, kinesthetic, and mixed imagery, while the imagery content has not been examined. To classify differences in the imagery content, five major types have been proposed (Hall, Mack, Paivio, \& Hausenblas, 1998; Paivio, 1985). These are (1) cognitive specific (CS; i.e., images of skills), (2) cognitive general (CG; i.e., images of strategies), (3) motivational specific (i.e., images of goals), (4) motivational general-arousal (MG-A, i.e., images of arousal and affect), and (5) motivational general-mastery (MG-M, i.e. imagery of cognitions including self-confidence and mental toughness. The cognitive specific function is conceptually akin to the term motor imagery 
(MI), as both involve the internal representation of motor skills without any corresponding body movements occurring (Guillot \& Collet, 2008). For the purpose of the current metaanalysis we included any type of imagery in the analyses and systematically investigated their effectiveness, respectively.

Third, previous meta-analyses demonstrated the effectiveness of mental practice compared to active and passive control groups without differentiating between differences in the active control groups (Feltz \& Landers, 1983; Hinshaw, 1991) or compared mental practice to active control groups without any practice components (Driskell et al., 1994; Toth et al., 2020). In the field of imagery reasearch, most commonly active control groups receive physical practice (e.g., Guillot, Tolleron, \& Collet, 2010; O \& Munroe-Chandler, 2008; Shackell \& Standing, 2007; Spittle \& Kremer, 2010), another sport psychological intervention (e.g., Gordon, Weinberg, \& Jackson, 1994; Kim, Frank, \& Schack, 2017), or another intervention, not related to the sports task (e.g., Robin et al., 2007). More specifically, imagery combined with physical practice vs. a physical practice control group is a common form of the application of imagery in research and practical settings (e.g., Brouziyne \& Molinaro, 2005; Frank, Land, \& Schack, 2016; C. Wright \& Smith, 2009) but has not been considered in the previous meta-analyses. To extend the findings of the previous meta-analyses and to estimate the effectiveness of imagery compared to different control groups, the current meta-analysis included any kind of control group and systematically investigated variations in the effectiveness of imagery interventions.

Fourth, previous meta-analyses used different type of comparisons to determine the effects of mental practice potentially leading to different magnitudes in effect sizes. While the previous meta-analyses included both, pre-post and post-post comparisons (Feltz \& Landers, 1983; Hinshaw, 1991), or post-post comparisons only (Driskell et al., 1994), the most recent metaanalysis used pre-post gains to operalize the change due to the mental practice (Toth et al., 2020). Until now, no systematic analysis investigating differences in the magnitude of effect sizes due to variations in the type of comparison exists. Such an analysis is, however, useful to 
provide benchmark data allowing valid comparisons across studies and a-priori sample size calculations (Moher, Dulberg, \& Wells, 1994; Schweizer \& Furley, 2016). We therefore invesigated the effects of imagery interventions taking all possible types of comparison into account and systematically investigating possible differences.

Fifth, while all meta-analyses used current statistical methods for their analyses when they were published, application of modern techniques of meta-analytic aggregation can further extend the validly and generalizability of their findings. For example, all previous metaanalyses except for the Toth et al. (2020) meta-analysis ignored the distinction between correlated designs and independent group designs, why conclusions reached from the metaanalytic results must be questioned (Dunlap, Cortina, Vaslow, \& Burke, 1996). Further, all previous meta-analyses combined various effect sizes per study. This is problematic as ignoring covariance at the study level can result in biased standard errors and confidence interval coverage proportions (e.g., Van den Noortgate, López-López, Marín-Martínez, \& SánchezMeca, 2013). Lastly, none of the previous meta-analyses performed outlier analyses and only few analyses regarding publication bias, possibly limiting the validity of the found results. Novel techniques of meta-analysis allow the inclusion of more than one effect size per study by statistically accounting for the dependency (e.g., Hedges, Tipton, \& Johnson, 2010) and enabling comprehensive outlier and publication bias analyses (e.g., Viechtbauer \& Cheung, 2010). In the present meta-analysis, we tried to extend the results found in previous metaanalyses by using robust methods for aggregating and analyzing the available data metaanalytically.

\section{The Present Meta-Analysis}

Imagery is one of the most researched psychological skills within the field of sport psychology and is widely accepted in practical settings to enhance performance. Despite the contribution of previous meta-analyses on the effectiveness of mental practice on performance, the quantitative summary of the existing empirical evidence on the effects of 
different types of imagery interventions and the effect on various outcomes in sports is still outstanding. Further, effects of methodical aspects, for example using different control groups and types of comparisons to determine the effectiveness of imagery, are not well understood yet. The present study has aims to add to previous meta-analyses and fill this gap in the literature on imagery interventions in sports.

We a-priori formulated the following five research questions and hypotheses:

1. Is imagery effective to enhance sport related outcomes and is the effect causal? We expect to find a positive and causal effect of imagery on any sports related outcomes (Hypothesis 1).

2. Is imagery effective when compared to a passive and an active control condition? Moreover, is physical practice combined with imagery more effective than physical practice alone? We assume that the overall effect of imagery interventions compared to different control conditions is positive (Hypothesis 2a) and that physical practice combined with imagery is more effective than physical practice alone. (Hypothesis 2b).

3. Does the magnitude of the effect of imagery vary due to different comparisons employed? We expected to find a higher effect for pre-post comparisons compared to effects for post-post and pre-post gains comparisons (Hypothesis 3).

4. Is imagery effective to enhance performance and other sport specific outcomes? We assume an effectiveness of imagery on various outcomes (Hypothesis 4) (Guillot \& Collet, 2008; Martin et al., 1999).

5. Are different types of imagery (equally) effective? We assume to find positive effects for all different types of imagery and to obtain no differences between them in their effectiveness (Hypothesis 5). 
Besides these main moderators, we included many others for exploratory moderator analyses retrieved from models on imagery frequently discussed in the literature (Cumming \& Williams, 2013; Guillot \& Collet, 2008; Holmes \& Collins, 2001; Martin et al., 1999).

\section{Method}

\section{Literature Search and Study Selection}

We searched the title, abstract, and keywords of all articles in the literature database PsycINFO and PubMed in January 2018 with a standardized search string and limited the results to studies with human populations that had been published in a peer-reviewed journal in English language. We did not limit the search to publication years. The standardized search with the respective keyword combination and restrictions provided 290 hits in total. We also identified relevant studies via hand search by looking through references of published metaanalyses on mental practice and reviews on imagery (Cooley, Williams, Burns, \& Cumming, 2013; Driskell et al., 1994; Feltz \& Landers, 1983; Hinshaw, 1991; Schuster et al., 2011). The hand search identified 62 additional eligible studies. Following, the systematic search and hand search resulted in 372 relevant hits for this meta-analysis. Figure 1 summarizes the search process in a PRISMA flow chart (Moher, Liberati, Tetzlaff, \& Altman, 2009). We accounted for publication bias by using visual and statistical methods (described in the section Statistical Analyses below) instead of including unpublished studies. The quality of unpublished studies is hard to assess, and researchers commonly obtain only a nonrepresentative set of unpublished studies, which does not increase the quality of the metaanalytic results (Ferguson \& Brannick, 2011; Rothstein \& Bushman, 2012).

\section{Inclusion of Studies}

Inclusion of studies followed four inclusion criteria: (1) The study reported quantitative non-confounded data on effects of an imagery intervention. The effect could either pertain to within or between comparisons. Therefore, single case studies, studies with single subject designs and qualitative studies were excluded. We did not include studies/effect sizes 
comparing one imagery intervention to another imagery intervention or effect sizes where the treatment group differed in more than the imagery implementation compared to the control group. Studies combining imagery with other mental strategies were sampled, but only for comparison with studies using pure imagery interventions. Studies were also excluded if they implemented preparatory imagery before movement execution. (2) The imagery content/outcome had to be sports specific. (3) Effects of the imagery intervention had to pertain to measures assessed before and after the intervention. Studies exclusively assessing online measures during imagery were excluded. (4) The study had to report original empirical findings (i.e., not a re-analysis of already reported findings or a review) to avoid double coding of effect sizes.

Coding of studies occurred in two steps. First, all abstracts were screened by the first author to evaluate relevance for the present study. The third author independently screened a random sample of 71 studies. The absolute intercoder agreement was 96\%. Disagreements were resolved by discussion. A total of 167 abstracts were classified as eligible for further inspection of the full texts. Second, the 167 full texts were assessed for eligibility. The second author coded all full texts; the first and third authors coded half of the full texts, respectively. Overall, 55 studies were identified as relevant for the present meta-analysis. The intercoder agreement for the in- and exclusion of studies based on inspection of the full texts was $91 \%$. The overall intercoder agreement for the coding of all moderating variables and effect sizes was $88 \%$. Disagreements were again resolved by discussion. The studies included in the meta-analysis are listed in the Supplemental Materials. Whenever data was missing to compute the effect sizes of interest, we requested this information from the authors of the paper by email.

\section{Data Coding}

We coded all effect sizes reported in the included studies and did not limit the number of effects included from each study, because studies using several groups, outcomes, or 
measurement points frequently reported several relevant comparisons. To maximize comparability across studies, we coded the raw data (i.e., the means and standard deviations of the outcome measures) instead of the reported effect sizes whenever possible and computed a standardized effect size the same way for each study, as described in the Supplemental Materials. For each included effect, we coded the values of the moderators.

\section{Preparation of Effect Sizes}

For each effect, we computed the effect size Cohen's $d$ from the coded raw data using syntax (for more details, see the Supplemental Materials). For 61 effect sizes, raw data was not available. Instead, we included the reported Cohen's $d$ values or the transformed $\chi 2$ values, $t$-values or $F$-values. We analysed three different types of comparisons (pre-post, postpost, and pre-post gains comparisons) to estimate the overall effectiveness of imagery interventions which is described in the Supplemental Material in more details.

We performed a bare bones meta-analysis and did not statistically adjust the effect sizes for study artifacts (Schmidt \& Hunter, 2015), as only few studies reported the reliabilities for the employed measures. As sensitivity analyses, we performed the meta-analysis with and without attenuation for study artefacts and with small sample correction calculating Hedge's $g$ instead of Cohen's $d$. The alternative approaches did not meaningfully change the overall effect sizes and moderating effects.

\section{Statistical Analysis}

Before aggregation of data from single studies, we identified outliers using specific outlier diagnostics for meta-analysis (Viechtbauer \& Cheung, 2010). Based on the examination of studentized deleted residuals, DFFITS values, Cook's distances, and COVRATIO values (for more details see Viechtbauer \& Cheung, 2010), we removed two effect sizes out of one study (Afrouzeh, Sohrabi, Haghkhan, Rowshani, \& Goharrokhi, 2015).

Most of the included studies provided multiple effect sizes for the effects of an imagery intervention. Consequently, effect sizes were statistically dependent. We addressed this 
problem by using robust variance estimation (RVE, Hedges et al., 2010; Tanner-Smith \& Tipton, 2014; Tanner-Smith, Tipton, \& Polanin, 2016). Random effects statistical models were used for all analysis (Raudenbush, 2009), to address the presumed heterogeneity of effects. First, we estimated a simple RVE meta-regression model to estimate the overall effect of imagery interventions. Second, to estimate the variability in the effect size due to moderator variables, we estimated a mixed-effects RVE meta-regression model (for more details, see the Supplemental Material). We used the robumeta package (Fisher \& Tipton, 2014) in the R statistical environment (R Core Team, 2008) for the analyses.

Meta-analyses can be subject to publication bias (Polanin, Tanner-Smith, \& Hennessy, 2016; Rothstein, Sutton, \& Borenstein, 2005). To address this problem we conducted visual analysis using funnel plots (Lau, Ionnidis, Terrin, Schmidt, \& Olkin, 2006) and statistical analysis using Egger's regression (Egger, Smith, Schneider, \& Minder, 1997), and trim-andfill analyses (Duval \& Tweedie, 2000).

\section{Results}

\section{Study Characteristics}

A total of 55 studies reporting 401 effect sizes obtained with 1,438 participants were included in the final meta-analysis. The studies were published between 1960 and 2018 with a median publication year of 2005. The sample size varied between 5 and 106 participants with a mean of 24.36 participants. The mean age of the participants ranged from 9 to 40 with a mean age of 22 years. A screening of imagery ability occurred in $44 \%$ of the studies. The majority of participants did not have any previous experience with imagery.

Most effect sizes were from randomized controlled trials (62\%), followed by controlled trials $(26 \%)$, and pre-post comparisons $(12 \%)$. Studies included outcomes of motor learning and performance (77\%), psychological skills (11\%), motivational outcomes (8\%), affective outcomes (3\%), and strategies and problem solving $(2 \%)$. 


\section{Hypothesis 1}

Table 2 summarizes all results of the meta-analysis. The meta-analytically obtained overall effect size based on 401 effect sizes from 55 studies indicated a positive, medium, and statistically significant effect of imagery with Cohen's $d=0.431,95 \%$ CI $[0.298,0.563]$. The effect was also significantly positive for randomized controlled trials, indicating a causal effect of imagery with $d=0.254$ (95\% CI [0.179, 0.530]). Effects of imagery were evident in both, no retention and retention tests, indicating lasting changes due to the intervention.

\section{Hypothesis 2}

The effectiveness of imagery was significantly better compared to a passive control group (no intervention, no physical practice, $d=0.508,95 \%$ CI $[0.281,0.735]$ ) and an active control group without physical practice (another intervention, no physical practice, $d=0.484,95 \% \mathrm{CI}$ $[0.069,0.898)$. Imagery combined with physical practice was more effective as physical practice alone $(d=.156,95 \%$ CI $[0.002,0.310)$. We repeated this analysis for motor outcomes only, which revealed the same result $(d=.231,95 \%$ CI $[0.060,0.402)$. Overall, the effects of imagery were comparable to effects of regular practice $(d=.125,95 \%$ CI [-0.175, 0.431]). Moderation analyses did not indicate any differences across the different control conditions with $F(7.38)=0.404, p=.755$.

\section{Contributing Factors to the Effectiveness of Imagery Interventions}

\section{Hypothesis 3}

Regarding hypothesis 3, imagery was effective to enhance motor learning and performance ( $d$ $=0.468,95 \% \mathrm{CI}[0.303,0.633)]$, motivational outcomes $(d=0.348,95 \%$ CI $[0.033,0.663)]$, and affective outcomes $(d=0.269,95 \%$ CI $[0.001,0.537)]$. There were no statistically relevant difference in the magnitude if the effect depending on the different outcomes $(F(5.89)=1.32, p=.353)$. Thus, the results provide evidence for our third hypothesis, indicating the effectiveness of imagery interventions for performance but also psychological outcomes. 


\section{Hypothesis 4}

Effectiveness of imagery intervention varied due to the employed comparison $(F(16.90)=$ $7.53, p=.005)$. The effect was largest for pre-post comparisons $(d=0.934,95 \%$ CI $[0.571$, $1.300)]$, followed by post-post comparisons $(d=0.570,95 \% \mathrm{CI}[0.188,0.953)]$, and pre-post gains $(d=0.260,95 \%$ CI $[0.122,0.398)]$. We performed the same analyses holding study characteristics constant. From the set of 32 studies and 278 effect sizes, results were comparabale with the largest effect for pre-post comparisons $(d=0.727,95 \% \mathrm{CI}[0.548$, $0.906)]$, followed by post-post comparisons $(d=0.339,95 \%$ CI $[0.166,0.511)]$, and pre-post gains $(d=0.232,95 \%$ CI $[0.097,0.368)]$. Summarizing, effect sizes significantly vary in magnitude due to the employed comparison, as expected in our fourth hypothesis.

\section{Hypothesis 5}

Only few studies reported their employed imagery type, leading to insufficient power to determine effect sizes and moderation analyses. Whenever stated in the single studies, CS imagery was implemented most commonly, followed by MG-M imagery, MG-A imagery, and other types of imagery. Cognitive specific imagery was effective to enhance sport specific outcomes with $d=0.304,95 \%$ CI $[0.135,0.473)]$. Due to the lack of studies and resulting limited power, we were not able to perform any statistical analyses regarding out fifth hypothesis.

\section{Exploratory Moderators}

Of all included moderators, the only significant moderator was the number of sessions of the imagery training. The effectiveness was significantly higher the more sessions the implementation included $(F(18)=11, p=.004)$. None of the other moderators reached significance, demonstrating a robust effect of imagery across different age groups, imagery specifics, and settings.

\section{Checks for Publication Bias}


Visual inspection of the funnel plot (see Figure 2) for the study level (i.e., the average effect size of each study) and effect size level (i.e. all 401 effect sizes) and Egger regressions for random effects (Egger et al., 1997) did not indicate significant asymmetry on study level and effect size level. Trim and fill (Duval \& Tweedie, 2000) did not indicate any missing studies, keeping the results of the meta-analysis unchanged. The results suggest that our findings are unlikely distorted by publication bias.

\section{Discussion}

\section{Effectiveness of Imagery Interventions}

The main goal of the meta-analysis was to extend previous meta-analyses on mental practice by examining the overall effects of imagery on sport specific outcomes together with its robustness, and to identify relevant moderating variables. We summarize the results of the meta-analysis in five key findings. First, imagery is effective to enhance not only performance but also other sport specific outcomes. Second, imagery significantly enhances the effects of physical practice. Third, the magnitude of effect sizes vary across different types of comparisons. Fourth, imagery effects are dosage specific. Fifth, there still exist many gaps in literature on imagery. While the different theories and models include a variety of variables proposed to be relevant for successful imagery interventions, there is a lack in empirical evidence of the relevance of these variables.

\section{Key Finding 1}

As expected, imagery was effective to enhance sport specific outcomes with an overall effect size of $d=0.431$. The obtained effect size summarizing various sport specific outcomes is comparable to previous meta-analyses on mental practice focusing on performance outcomes, which found an effect sizes of $d=0.527$ and $d=0.419$ (Driskell et al., 1994; Toth et al., 2020). It is also comparable to the effects from other meta-analyses investigating effects of psychological interventions on sports performance, such as goal setting (Kyllo \& Landers, 1995) or self-talk interventions (Hatzigeorgiadis, Zourbanos, Galanis, \& Theodorakis, 2011). 
The effect of imagery is rather causal than correlation, as the effect was still present in randomized controlled trials holding third variables constant. The effectiveness of imagery was significant when compared to both, a passive control group and an active control group. Results suggest a long-term effect as the effectiveness was demonstrated in retention tests. It was further evident across a variety of different participant, intervention, and outcome characteristics, indicating a robust effect of imagery across different settings.

Key Finding 2

Imagery combined with physical practice was more effective than physical practice alone, which follows the assumption that imagery enhances the effects of physical practice (e.g., Hall, Buckolz, \& Fishburne, 1992). From a theoretical perspective, imagery and physical practice share similar neural substrate, although corresponding neural networks are not totally overlapping (e.g., Decety et al., 1994; Gerardin et al., 2000; Guillot et al., 2008). More recently, it has been discussed that combined mental and physical practice is superior to physical practice alone as there might be differential influences of mental practice and physical practice (e.g., Frank et al., 2016; Guillot, Moschberger, \& Collet, 2013). Another explanation might be that the combined practice group had more practice trials as compared to the physical practice group. However, when analysing the effectiveness of studies with equal practice trials (e.g., imagery plus physical practice vs. physical practice plus a filler task), the effect of imagery was still positive and significant, both on motor tasks and other tasks. Therefore, the results of the current meta-analysis also indicate differential influences of imagery and physical practice. Furthermore, the differential effects are likely to be found for both, motor performance, and other sport specific outcomes such as psychological outcomes.

\section{Key Finding 3}

We demonstrate that the magnitude of effect size for imagery interventions differs due to the type of comparison. Our results highlight the relevance to account for different 
comparisons, as pre-post effects significantly differ from post-post effects and pre-post gains. The last comparison is most appropriate for intervention studies that focus on learning or improvement in specific variables as it represents the change due to an intervention (e.g., Hake, 1998; Nissen, Talbot, Thompson, \& Van Dusen, 2018; R. H. Williams \& Zimmerman, 1996). Studies aiming to investigate change in specific variables due to an imagery intervention should therefore report gain scores whenever possible. Many studies reported the relevant information for the computation of gains scores, but did not report the effect size respectively. One reason why studies do not report gain scores might be that gain scores were once thought to have undesirable statistical characteristics, for example, chronically low reliabilities. Newer studies, however, show that these conclusions are based on unrealistic statistical assumptions and that gain scores can have acceptable validities and reliabilities under more realistic assumptions (Maris, 1998; May \& Hittner, 2010; Zimmermann \& Williams, 1998).

\section{Key Finding 4}

Effects of imagery are dosage specific. Our results suggest that the more sessions employed, the more effective the imagery intervention. This results support the results from previous meta-analyses and reviews, also indicating dosage specific effects of mental practice (Driskell et al., 1994; Hinshaw, 1991; Toth et al., 2020) and imagery interventions (Cooley et al., 2013). The results further support expertise theory, suggesting that the time an individual is engaged in deliberate practice activities is monotonically related to performance enhancements (Ericsson, Krampe, \& Tesch-Römer, 1993). Deliberate practice is any type of practice activity with the aim to improve performance. Imagery has been described as one form of deliberate practice in sport (Cumming \& Hall, 2002). Given that imagery is more effective the more sessions employed, our findings provide evidence for the potential of imagery as one form of deliberate practice.

\section{Key Finding 5}


There exist many gaps in research on imagery, resulting in an underrepresentation of some moderators in our analyses. While theories and models include a variety of variables considered relevant for imagery to be successful, their effect remains to be determined. On a descriptive level, we found great differences in the magnitude of effect size regarding, for example, imagery type, the participants' imagery ability or skill level, the employed perspective, or temporal equivalence of the imagery. However, we were not able to test these differences statistically due to a small number of studies within one category. One reason may be the complex nature of imagery and the large amount of differences in the implementation. In turn, it needs a great amount of studies to test differences in the effectiveness caused by the specifics of imagery and implementation systematically. To understand the impact of characteristics of the participants, the specifics of imagery and the implementation strategies, more empirical investigations are needed that thoroughly test the variety of variables of models on imagery (Cumming \& Williams, 2013; Guillot \& Collet, 2008; Holmes \& Collins, 2001).

\section{Directions for Future Research}

In light of the current meta-analysis, at least three suggestions for future research can be proposed. First, specifics of imagery greatly varied across studies, resulting in few studies within each moderator category. To fully understand the effectiveness of imagery and under which condition imagery is most effective, more research is needed that tests assumptions of current models on imagery. The summary of previous studies in our meta-analysis gives a comprehensive overview of remaining gaps in literature. For example, future studies could investigate the effects of imagery other than cognitive specific imagery (e.g., Martin et al., 1999; Munroe-Chandler, Hall, Fishburne, Murphy, \& Hall, 2012) or differences in the effectiveness of imagery due to participant characteristics, such as imagery ability (e.g., S. E. Williams \& Cumming, 2011) and expertise (Guillot et al., 2008; Simonsmeier, Frank, Gubelmann, \& Schneider, 2018). Further, variations in the implementation, such as temporal 
equivalence or imagery perspective (e.g., Cumming \& Ste-Marie, 2001; Holmes \& Collins, 2001) can be considered in future studies. Replication of existing results and extension of empirical evidence is necessary to test whether the results generalize to other settings and other populations.

Second, most of the outcomes related to motor performance. Only few studies investigated the effects of imagery on psychological skills, such as imagery use (e.g., Cumming \& Ste-Marie, 2001; Munroe-Chandler, Hall, Fishburne, \& Shannon, 2005) and imagery ability (e.g., Cumming \& Ste-Marie, 2001; D. J. Wright, McCormick, Birks, Loporto, \& Holmes, 2015), motivational outcomes (e.g., Martin \& Hall, 1995; Ramsey, Cumming, Edwards, Williams, \& Brunning, 2010), or affective outcomes (e.g., Mellalieu, Hanton, \& Thomas, 2009; Ramsey et al., 2010). Future research may extent the understanding of the effectiveness of imagery by investigating effects of imagery on other outcomes than performance.

Third, the quality of future studies and meta-analyses may be enhanced by critically deciding for a specific research design, control groups, comparison, and more precisely reporting the procedure of an intervention (e.g., Goginsky \& Collins, 1996). We had to exclude a great number of studies for methodological reasons or reporting issues, such as missing data (e.g., missing means or standard deviations) or confounding variables (e.g., combination of imagery with other mental strategies). Researchers should conscientiously decide on how they report characteristics of their studies to ensure replicability. In our case, most imagery interventions were described incomplete, resulting in fewer effect sizes that could be included in moderator analyses as compared to the amount of effect sizes included in the general analysis.

\section{Generalizability of the Findings and Conclusion}

The medium positive effect of imagery in sport specific outcomes reported in the present meta-analysis can be interpreted as non-confounded effects of imagery, as studies were only 
included when the intervention and control condition only differed in the implementation of imagery (e.g., imagery compared to no intervention) and nothing else (e.g., imagery combined with physical practice compared to no intervention). As the effect of imagery was still significant for randomized controlled trials, possible influences of third variables can be ruled out. The effects were robust as compared to passive control groups and active control groups implementing another intervention. Further, effects of imagery were evident in both no retention and retention tests, indicating lasting changes due to the intervention. In our analysis, we accounted for publication bias and the dependencies of effect sizes, and had sufficient coding reliability to increase the validity of our findings.

Due to the great variety in the implementation of imagery interventions, some moderators were underrepresented. For example, there is little evidence on the effects of imagery for participants with low imagery ability, professional athletes, or participants with imagery experience. Similarly, only few studies investigated the effects of imagery types other than cognitive specific imagery. Furthermore, some specific characteristics of the imagery implementation were considered in few studies only, for example variations in timing, the perspective, or the sensory modalities included. This resulted in limited power for some analyses.

Overall, imagery was confirmed to be an effective strategy for enhancing various outcomes in sports. Furthermore, we identified moderators that could further explain the effects of imagery, enhance our knowledge regarding the effectiveness of imagery interventions, and provide directions for future research. The medium effect of imagery in sport, as determined by the present meta-analysis, encourages the promotion and use of imagery by athletes, sport educators, coaches, and sport psychologists. The obtained data in this meta-analysis may serve as benchmark data for future studies with varying designs (e.g., within or between comparisons) and comparisons (e.g. post-post comparisons or pre-post gain comparisons) and can be used for a-priori power analyses. As such, we hope that this meta- 
analysis provides new and valid insights into the impact of imagery on various outcomes in sports. 


\section{References}

Afrouzeh, M., Sohrabi, E., Haghkhan, A., Rowshani, F., \& Goharrokhi, S. (2015). Effectiveness of PETTLEP imagery on performance of passing skill in volleyball. The Journal of Sports Medicine And Physical Fitness, 55(1-2), 30-36

Borenstein, M. (2009). Effect sizes for continuous data. In H. Cooper, L. V. Hedges \& J. C. Valentine (Eds.), The handbook of research synthesis and meta-analysis (2nd ed., pp. 221-235). New York: Russel Sage Foundation.

Brouziyne, M., \& Molinaro, C. (2005). Mental imagery combined with physical practice of approach shots for golf beginners. Perceptual and Motor Skills, 101(1), 203-211. doi: 10.2466/PMS.101.5.203-211

Callow, N., Hardy, L., \& Hall, C. (2001). The effects of a motivational general-mastery imagery intervention on the sport confidence of high-level badminton players. Research Quarterly of Exercise and Sport, 72(4), 389-400. doi: http://dx.doi.org/10.1080/02701367.2001.10608975

Cooley, S. J., Williams, S. E., Burns, V. E., \& Cumming, J. (2013). Methodological variations in guided imagery interventions using movement imagery scripts in sport: A systematic review. Journal of Imagery Research in Sport and Physical Activity, 8(1), 13-34. doi: 10.1515/jirspa-2012-0005

Cumming, J., \& Hall, C. (2002). Deliberate imagery practice: The development of imagery skills in competitive athletes. Journal of Sports Sciences, 20(2), 137-145. doi: $10.1080 / 026404102317200846$

Cumming, J., \& Ramsey, R. (2009). Imagery interventions in sport. In S. Mellalieu \& S. Hanton (Eds.), Advances in applied sport psychology: A review (pp. 5-36). London: Routledge.

Cumming, J., \& Ste-Marie, D. M. (2001). The cognitive and motivational effects of imagery training: A matter of perspective. The Sport Psychologist, 15(3), 276-288. doi: 10.1123/tsp.15.3.276

Cumming, J., \& Williams, S. E. (2013). Introducing the revised applied model of deliberate imagery use for sport, dance, exercise, and rehabilitation. Movement \& Sport Sciences, 82, 69-81. doi: $10.1051 / \mathrm{sm} / 2013098$ 
Decety, J., D., P., M., J., V., B., B., T., R.P., W., . . F., F. (1994). Mapping motor representations with positron emission tomography. Nature, 371, 600-602. doi: 10.1038/371600a0

Driskell, J. E., Copper, C., \& Moran, A. (1994). Does mental practice enhance performance? Journal of Applied Psychology, 79(4), 481-492. doi: 10.1037/0021-9010.79.4.481

Dunlap, W. P., Cortina, J. M., Vaslow, J. B., \& Burke, M. J. (1996). Meta-Analysis of experiments with matched groups or repeated measures designs. Psychological Methods, 1(2), 170-177. doi: 10.1037/1082-989X.1.2.170

Duval, S., \& Tweedie, R. (2000). A nonparametric "trim and fill" method of accounting for publication bias in meta-analysis. Journal of the American Statistical Association, 95(449), 89-98. doi: $10.2307 / 2669529$

Egger, M., Smith, G. D., Schneider, M., \& Minder, C. (1997). Bias in meta-analysis detected by a simple, graphical test. British Medical Journal, 315, 629-634. doi: 10.1136/bmj.315.7109.629

Ericsson, K. A., Krampe, R. T., \& Tesch-Römer, C. (1993). The role of deliberate practice in the acquisition of expert performance. Psychological Review, 100(3), 363-406. doi: $10.1037 / / 0033-295 \times .100 .3 .363$

Feltz, D. L., \& Landers, D. M. (1983). The effects of mental practice on motor skill learning and performance: A meta-analyses. Journal of Sport Psychology, 5(1), 25-57. doi: 10.1123/jsp.5.1.25

Ferguson, C. J., \& Brannick, M. T. (2011). Publication bias in psychological science: Prevalence, methods for identifying and controlling, and implications for the use of meta-analyses. Psychological Methods, 17(1), 120-128. doi: 10.1037/a0024445

Fisher, Z., \& Tipton, E. (2014). Robumeta: Robust variance meta-regression. Retrieved from http://cran.rproject.org/web/packages/robumeta/index.html

Frank, C., Land, W. M., \& Schack, T. (2016). Perceptual-cognitive changes during motor learning: the influence of mental and physical practice on mental representation, gaze behavior, and performance of a complex action. Frontiers in Psychology, 6, Article 1981. doi: 10.3389/fpsyg.2015.01981 
Gerardin, E., Sirigu, A., Lehericy, S., Poline, J. B., Gaymard, B., Marsault, C., . . L Le Bihan, D. (2000). Partially overlapping neural networks for real and imagined hand movements. Cerebral Cortex, 10(11), 1093-1104. doi: 10:1093-1104

Goginsky, A. M., \& Collins, D. (1996). Research design and mental practice. Journal of Sports Sciences, 14(5), 381-392. doi: 10.1080/02640419608727725

Gordon, S., Weinberg, R., \& Jackson, A. (1994). Effect of internal and external imagery on cricket performance. Journal of Sport Behavior, 17(1), 60-75

Guillot, A., \& Collet, C. (2008). Construction of the Motor Imagery Integrative Model in sport: A review and theoretical investigation of motor imagery use. International Review of Sport and Exercise Psychology, 1(1), 31-44. doi: 10.1080/17509840701823139

Guillot, A., Collet, C., Nguyen, V. A., Malouin, F., Richards, C., \& Doyon, J. (2008). Functional neuroanatomical networks associated with expertise in motor imagery. Neurolmage, 41, 1471-1483. doi: 10.1016/j.neuroimage.2008.03.042

Guillot, A., Moschberger, K., \& Collet, C. (2013). Coupling movement with imagery as a new perspective for motor imagery practice. Behavioral and Brain Functions, 9(1), 8. doi: 10.1186/1744-90819-8

Guillot, A., Tolleron, C., \& Collet, C. (2010). Does motor imagery enhance stretching and flexibility? Journal of Sports $\quad$ Sciences, 28(3), 291-298. doi: http://dx.doi.org/10.1080/02640410903473828

Hake, R. R. (1998). Interactive-engagement versus traditional methods: A six-thousand-student survey of mechanics test data for introductory physics courses. American Journal of Physics, 66(1), 6474. doi: $10.1119 / 1.18809$

Hale, B. D., \& Whitehouse, A. (1998). The effects of imagery-manipulated appraisal on intensity and direction of competitive anxiety. The Sport Psychologist, 12(1), 40-51. doi: http://dx.doi.org/10.1123/tsp.12.1.40

Hall, C., Buckolz, E., \& Fishburne, G. J. (1992). Imagery and acquisition of motor skills. Canadian Journal of Sport Sciences, 17(1), 19-27 
Hall, C., Mack, D. E., Paivio, A., \& Hausenblas, H. A. (1998). Imagery use by athletes: Development of the sport imagery questionnaire. International Journal of Sport Psychology, 29(1), 73-89

Hammond, T., Gregg, M., Hrycaiko, D., Mactavish, J., \& Leslie-Toogood, A. (2012). The effects of a motivational general-mastery imagery intervention on the imagery ability and sport confidence of inter-collegiate golfers. Journal of Imagery Research in Sport and Physical Activity, 7(1), Article 3. doi: 10.1515/1932-0191.1066

Hatzigeorgiadis, A., Zourbanos, N., Galanis, E., \& Theodorakis, Y. (2011). Self-talk and sports performance: A meta-analysis. Perspectives on Psychological Science, 6(4), 348-356. doi: $10.1177 / 1745691611413136$

Hedges, L. V., Tipton, E., \& Johnson, M. C. (2010). Robust variance estimation in meta-regression with dependent effect size estimates. Research Synthesis Methods, 1(2), 39-65. doi: 10.1002/jrsm.5

Hinshaw, K. E. (1991). The effects of mental practice on motor skill performance: Critical evaluation and meta-analysis. Imagination, Cognition and Personality, 11(1), 3-35

Holmes, P. S., \& Collins, D. J. (2001). The PETTLEP approach to motor imagery: A functional equivalence model for sport psychology. Journal of Applied Sport Psychology, 13(1), 60-83. doi: $10.1080 / 10413200109339004$

Kim, T., Frank, C., \& Schack, T. (2017). A systematic investigation of the effect of action observation training and motor imagery training on the development of mental representation structure and skill performance. Frontier in Human Neuroscience, 11, 499. doi: 10.3389/fnhum.2017.00499

Kyllo, L. B., \& Landers, D. M. (1995). Goal setting in sport and exercise: A research synthesis to resolve the controversy. Journal of Sport and Exercise Psychology, 17(2), 117-137. doi: 10.1123/jsep.17.2.117

Lau, J., Ionnidis, J. P. A., Terrin, N., Schmidt, C. H., \& Olkin, I. (2006). The case of the misleading funnel plot. British Medical Journal, 333(7568), 597-600. doi: 10.1136/bmj.333.7568.597

Maris, E. (1998). Covariance adjustment versus gain scores - revisited. Psychological Methods, 3, 309- 
Martin, K. A., \& Hall, C. R. (1995). Using mental imagery to enhance intrinsic motivation. Journal of Sport and Exercise Psychology, 17(1), 54-69. doi: 10.1123/jsep.17.1.54

Martin, K. A., Moritz, S. E., \& Hall, C. R. (1999). Imagery use in sport: A literature review and applied model. The Sport Psychologist, 13(3), 245-268. doi: 10.1123/tsp.13.3.245

May, K., \& Hittner, J. B. (2010). Reliability and validity of gain scores considered graphically. Perceptual and Motor Skills, 111, 399-406. doi: 10.2466/03.PMS.111.5.399-406

Mellalieu, S. D., Hanton, S., \& Thomas, O. (2009). The effects of a motivational general-arousal imagery intervention upon preperformance symptoms in male rugby union players. Psychology of Sport and Exercise, 10(1), 175-185. doi: 10.1016/j.psychsport.2008.07.003

Moher, D., Dulberg, C. S., \& Wells, G. A. (1994). Statistical power, sample size, and their reporting in randomized controlled trials. JAMA, 272(2), 122-124. doi: 10.1001/jama.1994.03520020048013

Moher, D., Liberati, A., Tetzlaff, J., \& Altman, D. G. (2009). Preferred reporting items for systematic reviews and meta-analyses: The PRISMA statement. PLoS Med, 6(7), e1000097. doi: 10.1371/journal.pmed.1000097

Morris, T., Spittle, M., \& Watt, A. P. (2005). Imagery in Sport. Campaign, IL: Human Kinetics.

Munroe-Chandler, K. J., Hall, C. R., Fishburne, G. J., Murphy, L., \& Hall, N. D. (2012). Effects of a cognitive specific imagery intervention on the soccer skill performance of young athletes: Age group comparisons. Psychology of Sport and Exercise, 13(3), 324-331. doi: 10.1016/j.psychsport.2011.12.006

Munroe-Chandler, K. J., Hall, C. R., Fishburne, G. J., \& Shannon, V. (2005). Using cognitive general imagery to improve soccer strategies. European Journal of Sport Science, 5(1), 41-49. doi: $10.1080 / 17461390500076592$

Murphy, S. M., \& Martin, K. A. (2002). The use of imagery in sport. In T. S. Horn (Ed.), Advances in sport psychology (2nd ed., pp. 405-439). Champaign, IL: Human Kinetics. 
Nissen, J. M., Talbot, R. M., Thompson, A. N., \& Van Dusen, B. (2018). A comparison of normalized gain and Cohen's d for analyzinggains on concept inventories. Physical Review Physics Education Research, 14(1), 010115. doi: doi.org/10.1103/PhysRevPhysEducRes.14.010115

O, J., \& Munroe-Chandler, K. J. (2008). The effects of image speed on the performance of a soccer task. The Sport Psychologist, 22(1), 1-17. doi: 10.1123/tsp.22.1.1

Paivio, A. (1985). Cognitive and motivational functions of imagery in human performance. Canadian Journal of Applied Sport Sciences, 10(4), 22S-28S

Polanin, J. R., Tanner-Smith, E. E., \& Hennessy, E. A. (2016). Estimating the difference between published and unpublished effect sizes: A meta-review. Review of Educational Research, 86(1), 207-136. doi: 10.3102/0034654315582067

R Core Team. (2008). R: A language and environment for statistical computing. Retrieved from http://www.R-project.org/

Ramsey, R., Cumming, J., Edwards, M. G., Williams, S., \& Brunning, C. (2010). Examining the emotion aspect of PETTLEP-based imagery with penalty taking in soccer. Journal of Sport Behavior, $33(3), 295-314$

Raudenbush, S. W. (2009). Analyzing effect sizes: Random-effects models. In H. Cooper, L. V. Hedges \& J. C. Valentine (Eds.), The handbook of research synthesis and meta-analysis (pp. 295-315). New York: Russell Sage Foundation.

Robin, N., Dominique, L., Toussaint, L., Blandin, Y., Guillot, A., \& Le Her, M. (2007). Effects of motor imagery training on service return accuracy in tennis: The role of imagery ability. International Journal of Sport and Exercise Psychology, 5(2), 175-186. doi: 10.1080/1612197X.2007.9671818

Rothstein, H. R., \& Bushman, B. J. (2012). Publication bias in psychological science: Comment on Ferguson and Brannick. Psychological Methods, 17(1), 129-136. doi: 10.1037/a0027128

Rothstein, H. R., Sutton, A. J., \& Borenstein, M. (2005). Publication bias in meta-analysis: Prevention, assessment and adjustments. Chichester, England: John Wiley.

Schmidt, F. L., \& Hunter, J. E. (2015). Methods of meta-analysis: Correcting error and bias in research findings (3rd ed.). Thousand Oaks, CA: Sage. 
Schuster, C., Hilfiker, R., Amft, O., Scheidhauer, A., Andrews, B., Butler, J., . . Ettlin, T. (2011). Best practice for motor imagery: A systematic literature review on motor imagery training elements in five different disciplines. BMC Medicine, 9(75), 1-35. doi: 10.1186/1741-7015-9-75

Schweizer, G., \& Furley, P. (2016). Reproducible research in sport and exercise psychology: The role of sample sizes. Psychology of Sport and Exercise, 23, 114-122. doi: 10.1016/j.psychsport.2015.11.005

Shackell, E. M., \& Standing, L. G. (2007). Mind over matter: Mental training increases physical strength. North American Journal of Psychology, 9(1), 189-200

Simonsmeier, B. A., Frank, C., Gubelmann, H., \& Schneider, M. (2018). The effects of motor imagery training on performance and mental representation of 7- to 15-year-old gymnasts of different levels of expertise. Sport, Exercise, and Performance Psychology. doi: 10.1037/spy0000117

Spittle, M., \& Kremer, P. (2010). Mental practice and the retention of motor learning: A pilot study. Perceptual and Motor Skills, 110(3), 888-896. doi: 10.2466/PMS.110.3.888-896

Tanner-Smith, E. E., \& Tipton, E. (2014). Robust variance estimation with dependent effect sizes: Practical considerations and a sfotware tutorial in Stata and SPSS. Research Synthesis methods, 5(1), 13-30. doi: 10.1002/jrsm.1091

Tanner-Smith, E. E., Tipton, E., \& Polanin, J. R. (2016). Handling complex meta-analytic data structures using robust variance estimates: A tutorial in R. Journal of Developmental and Life-Course Criminology, 2(1), 85-112. doi: 10.1007/s40865-016-0026-5

Toth, A. J., McNeill, E., Hayes, K., Moran, A. P., \& Campbell, M. (2020). Does mental practice still enhance performance? A 24 Year follow-up and meta-analytic replication and extension. Psychology of Sport and Exercise. doi: 10.1016/j.psychsport.2020.101672

Van den Noortgate, W., López-López, J. A., Marín-Martínez, F., \& Sánchez-Meca, J. (2013). Three-level meta-analysis of dependent effect sizes. Behavior Research Methods, 45, 576-594. doi: $10.3758 / \mathrm{s} 13428-012-0261-6$

Viechtbauer, W., \& Cheung, M. W.-L. (2010). Outlier and influence diagnostics for meta-analysis. Reserach Synthesis methods, 1(2), 112-125. doi: 10.1002/jrsm.11 
Wakefield, C., \& Smith, D. (2012). Perfecting practice: Applying the PETTLEP model of motor imagery. Journal of Sport Psychology in Action, 3(1), 1-11. doi: 10.1080/21520704.2011.639853

Williams, R. H., \& Zimmerman, D. W. (1996). Are simple gain scores obsolete? Applied Psychological Measurement, 20(1), 59-69. doi: 10.1177/014662169602000106

Williams, S. E., \& Cumming, J. (2011). Measuring athlete imagery ability: The Sport Imagery Ability Questionnaire. Journal of Sport and Exercise Psychology, 33(3), 416-440. doi: 10.1123/jsep.33.3.416

Wright, C., \& Smith, D. (2009). The effect of PETTLEP imagery on strength performance. International Journal of Sport and Exercise Psychology, 7(1), 18-31. doi: 10.1080/1612197X.2009.9671890

Wright, D. J., McCormick, S. A., Birks, S., Loporto, M., \& Holmes, P. S. (2015). Action observation and imagery training improve the ease with which athletes can generate imagery. Journal of Applied Sport Psychology, 27(2), 156-170. doi: 10.1080/10413200.2014.968294

Zimmermann, D. W., \& Williams, R. H. (1998). Reliability of gain scores under realistic assumptions about properties of pre-test and post-test scores. Mathematical and Statistical Psychology, 51, 343-351. doi: 10.1111/j.2044-8317.1998.tb00685.x 


\section{Table 1}

Characteristics of the previous four meta-analyses on mental practice

\begin{tabular}{|c|c|c|c|c|c|c|c|c|c|c|c|c|}
\hline Reference & $\begin{array}{l}\text { Standardized } \\
\text { search word } \\
\text { combination }\end{array}$ & $\begin{array}{l}\text { Range } \\
\text { years } \\
\text { included } \\
\text { studies }\end{array}$ & $\begin{array}{l}\text { Explicit inclusion } \\
\text { and exclusion } \\
\text { criteria }\end{array}$ & $\begin{array}{l}\text { Accounting } \\
\text { for } \\
\text { dependency } \\
\text { of effect } \\
\text { sizes }\end{array}$ & $\begin{array}{l}\text { Outlier/ } \\
\text { sensitivity } \\
\text { analysis }\end{array}$ & $\begin{array}{c}\text { Tests for } \\
\text { publication } \\
\text { bias }\end{array}$ & $\begin{array}{l}\text { Included control } \\
\text { conditions }\end{array}$ & $\begin{array}{l}\text { Included } \\
\text { types of } \\
\text { compariso } \\
\text { n }\end{array}$ & $\begin{array}{l}\text { Included } \\
\text { outcomes }\end{array}$ & $n(k)$ & $\begin{array}{c}d \\
{[95 \% \mathrm{CI}]} \\
\text { or } \\
(S D)\end{array}$ & $\begin{array}{l}\text { Significant } \\
\text { moderators }\end{array}$ \\
\hline $\begin{array}{l}\text { Feltz and } \\
\text { Landers } \\
(1983)\end{array}$ & N/A & $\begin{array}{c}1934- \\
1981\end{array}$ & $\begin{array}{l}\text { The only criterion } \\
\text { was that there be } \\
\text { a group that was } \\
\text { given only mental } \\
\text { practice and that } \\
\text { this group have } \\
\text { either pretest } \\
\text { scores or a control } \\
\text { group to which be } \\
\text { compared }\end{array}$ & no & no & $\begin{array}{l}\text { Compariso } \\
\mathrm{n} \text { effect } \\
\text { size } \\
\text { published } \\
\text { vs. } \\
\text { unpublishe } \\
\text { d studies }\end{array}$ & $\begin{array}{l}\text { - Simple control } \\
\text { - Motivational } \\
\text { control (no } \\
\text { practice } \\
\text { control group } \\
\text { with same } \\
\text { number of } \\
\text { scheduled } \\
\text { experimental } \\
\text { sessions) }\end{array}$ & $\begin{array}{l}\text { - Pre-post } \\
\text { - Post-post }\end{array}$ & Performance & $\begin{array}{c}60 \\
(146 \\
)\end{array}$ & $.48(.67)$ & $\begin{array}{l}\text { - Task type } \\
\text { - Published } \\
\text { vs. } \\
\text { unpublished } \\
\text { studies }\end{array}$ \\
\hline $\begin{array}{l}\text { Hinshaw } \\
(1991)\end{array}$ & N/A & $\begin{array}{c}1949- \\
1987\end{array}$ & $\begin{array}{l}\text { - One condition } \\
\text { mental practice } \\
\text { alone } \\
\text { (mental/physical } \\
\text { practice group } \\
\text { combined } \\
\text { excluded) } \\
\text { - Adequate control } \\
\text { - Provide the } \\
\text { necessary } \\
\text { statistics }\end{array}$ & no & no & N/A & $\begin{array}{l}\text { - Direct } \\
\text { - Motivation } \\
\text { (perform } \\
\text { unrelated tasks } \\
\text { in } \\
\text { experimental } \\
\text { sessions) }\end{array}$ & $\begin{array}{l}\text { - Pre-post } \\
\text { - Post-post }\end{array}$ & Performance & $\begin{array}{l}21 \\
(44)\end{array}$ & $.68(.11)$ & $\begin{array}{l}\text { - Type of } \\
\text { mental } \\
\text { practice } \\
\text { - Number of } \\
\text { mental } \\
\text { practice } \\
\text { (minutes) }\end{array}$ \\
\hline $\begin{array}{l}\text { Driskell et } \\
\text { al. (1994) }\end{array}$ & $\begin{array}{l}\text { 'mental } \\
\text { practice' }\end{array}$ & $\begin{array}{c}1934- \\
1991\end{array}$ & $\begin{array}{l}\text { - Reported (or } \\
\text { allowed the } \\
\text { retrieval of) tests } \\
\text { of performance } \\
\text { under a mental } \\
\text { practice condition } \\
\text { in comparison } \\
\text { with a no- }\end{array}$ & no & no & - Fail safe & $\begin{array}{l}\text { - No-contact } \\
\text { control group } \\
\text { (e.g., wait-list) } \\
\text { - Equivalent } \\
\text { control group } \\
\text { (e.g., non- } \\
\text { treatment } \\
\text { activity) }\end{array}$ & Post-post & Performance & $\begin{array}{l}35 \\
(62)\end{array}$ & $\begin{array}{c}.527 \\
{[\mathrm{~N} / \mathrm{A}]}\end{array}$ & $\begin{array}{l}\text { - Duration of } \\
\text { mental } \\
\text { practice }\end{array}$ \\
\hline
\end{tabular}


treatment control

condition

- Compare the performance of participant

engaging in mental practice with those

engaging in $\mathrm{NO}$ practice

- An explicit NoPractice control group with

'mental practice' OR

Toth et al. 'imagery'

OR

$1995-$

(2020)

visualization

n' which to

compare mental practice group

performance

- Studies in which the mental

practice group

mentally

practice the

exact same task

as the one which

they were later

expected to
- Cognitively

active (e.g.,

mental

arithmetic)

- Fail- - Cognitively

safe N $\quad$ passive (e.g.,

reading)

- Minimal

cognitive

control (e.g.,

quiet rest)
- Duration of

mental

$\begin{array}{llll}\text { - Pre-post } & 37 & 0.419 & \text { practice }\end{array}$

(99) $\quad[0.246, \quad \bullet$ Type of task

- Type of

imagery

used 


\section{Table 2}

Number of studies $(j)$, number of effect sizes $(k)$, effect size $(d), 95 \%$ confidence interval, measure of heterogeneity $\tau^{2}$, and significance for the moderator analyses.

\begin{tabular}{|c|c|c|c|c|c|c|}
\hline Coding Options & $j$ & $k$ & $d$ & $95 \% C I$ & $\tau^{2}$ & Sign. moderator \\
\hline \multicolumn{7}{|l|}{$\begin{array}{l}\text { Methodological study } \\
\text { characteristics }\end{array}$} \\
\hline Study Design & & & & & & $*$ \\
\hline $\begin{array}{l}\text { Randomized } \\
\text { controlled trial }\end{array}$ & 30 & 249 & 0.254 & {$[0.179,0.530]$} & .202 & ref \\
\hline Controlled trial & 16 & 104 & 0.347 & {$[0.131,0.564]$} & .520 & $n s$ \\
\hline Pre-Post & 10 & 48 & 0.934 & {$[0.571,1.300]$} & .164 & $* *$ \\
\hline Control group & & & & & & $n s$ \\
\hline $\begin{array}{l}\text { No intervention, no } \\
\text { physical practice } \\
\text { control group }\end{array}$ & 17 & 51 & 0.508 & {$[0.281,0.735]$} & & $n s$ \\
\hline $\begin{array}{l}\text { No intervention, } \\
\text { physical practice } \\
\text { control group }\end{array}$ & 25 & 153 & 0.138 & {$[-0.045,0.322]$} & & ref \\
\hline $\begin{array}{l}\text { Another } \\
\text { intervention, no } \\
\text { physical practice } \\
\text { control group }\end{array}$ & 9 & 42 & 0.484 & {$[0.069,0.898]$} & & $n s$ \\
\hline $\begin{array}{l}\text { Another } \\
\text { intervention, } \\
\text { physical practice } \\
\text { control group }\end{array}$ & 10 & 107 & 0.488 & {$[0.125,0.851]$} & & $n s$ \\
\hline Comparison & & & & & & $* *$ \\
\hline Pre-post gains & 33 & 283 & 0.260 & {$[0.122,0.298]$} & $\begin{array}{c}0.26 \\
7\end{array}$ & ref \\
\hline Post-post & 11 & 61 & 0.570 & {$[0.188,0.953]$} & $\begin{array}{c}0.33 \\
6\end{array}$ & $n s$ \\
\hline Pre-post & 10 & 48 & 0.934 & {$[0.571,1.300]$} & $\begin{array}{c}0.16 \\
4\end{array}$ & $* *$ \\
\hline Retention Test & & & & & & $n s$ \\
\hline
\end{tabular}




\begin{tabular}{lcccccc}
\multicolumn{1}{c}{ Yes } & 8 & 26 & 0.429 & {$[0.252,0.572]$} & .236 & ref \\
\multicolumn{1}{c}{ No } & 52 & 368 & 0.441 & {$[0.252,0.572]$} & .337 & $n s$ \\
\hline $\begin{array}{l}\text { Outcome Category } \\
\begin{array}{l}\text { Motor learning and } \\
\text { performance }\end{array}\end{array}$ & 48 & 304 & 0.416 & {$[0.272,0.559]$} & .273 & $n s$ \\
$\begin{array}{l}\text { Strategies and } \\
\text { problem solving }\end{array}$ & 2 & 6 & 0.032 & - & - & - \\
$\begin{array}{l}\text { Affective } \\
\begin{array}{l}\text { Motivational } \\
\text { Psychological skills }\end{array}\end{array}$ & 6 & 13 & 0.269 & {$[0.001,0.537]$} & .161 & ref \\
& 7 & 30 & 0.351 & {$[0.003,0.699]$} & .151 & $n s$ \\
\hline
\end{tabular}

Imagery intervention

characteristics

Imagery Type

CS

MG-A

MG-M

Other

Sports

Archery

Basketball

Cricket

Darts

Field hockey

Figure Skating

Fitness

Golf

Gymnastics

Soccer $\begin{array}{lllll}24 & 194 & 0.304 & {[0.135,0.473]} & .186\end{array}$

$\begin{array}{lll}2 & 12 & 0.476\end{array}$

$\begin{array}{lll}3 & 15 & 0.907\end{array}$

$\begin{array}{lll}2 & 16 & -.0148\end{array}$ $n s$

$$
\begin{array}{lll}
2 & 7 & 0.005
\end{array}
$$

$\begin{array}{lll}6 & 33 & 0.524\end{array}$

$[0.026,1.020] \quad .104$

$n s$

$\begin{array}{lll}2 & 64 & 0.190\end{array}$

$\begin{array}{lll}3 & 10 & 0.309\end{array}$

$\begin{array}{lll}2 & 5 & 2.170\end{array}$

$\begin{array}{lll}2 & 33 & 0.297\end{array}$

855

0.161

$[-0.219,0.541] \quad .219$

ref

$\begin{array}{lllll}8 & 64 & 0.557 & {[0.144,0.970]} & .322\end{array}$

$n s$

\section{$\begin{array}{lll}3 & 14 & 0.455\end{array}$}

$\begin{array}{lll}3 & 21 & 0.265\end{array}$ 
Introduction

Yes

$23 \quad 144 \quad 0.491$

$[0.239,0.742] \quad .264$

ns

No

$28 \quad 244$

$0.445 \quad[0.289,0.600] \quad .334$

ref

Duration [days] cont. $\quad 53 \quad 386$

ns

Duration

[minutes/session]

$33 \quad 284$

ns

cont.

Number of sessions

cont.

$49 \quad 374$

Number of trials cont. $\quad 28 \quad 159$

$n s$

Modality of

instruction

Read aloud

$\begin{array}{lll}5 & 33 & .201\end{array}$

Audio tape

$7 \quad 80$

$0.418 \quad[-0.116,0.952] \quad .211$

ref

Inner self-talk

$\begin{array}{lll}35 & 252 & 0.501\end{array}$

$[0.303,0.698] \quad .391$

$n s$

Various

$\begin{array}{lll}3 & 17 & 0.433\end{array}$

Setting

Practice

$20 \quad 187$

0.242

$[0.080,0.403] \quad .171$

Outside of practice

$16 \quad 98$

0.611

$[0.231,0.992] \quad .543$

ref

Senses

Visual

$\begin{array}{lll}5 & 14 & 0.450\end{array}$

Kinesthetic

$\begin{array}{lll}5 & 76 & 0.232\end{array}$

Combination

$\begin{array}{lll}28 & 163 & 0.507\end{array}$

$[0.296,0.718] \quad .277$

Script

$n s$

Given

$\begin{array}{lll}23 & 183 & 0.440\end{array}$

$[0.238,0.642] \quad .231$

ref

Individual

$\begin{array}{lllll}20 & 150 & 0.538 & {[0.290,0.787} & .284\end{array}$

$n s$

Timing (Temporal equivalence)

$\begin{array}{cccccc}\text { Yes } & 14 & 81 & 0.568 & {[0.214,0.922]} & .350 \\ \text { No } & 3 & 67 & 0.045 & - & -\end{array}$


Mixed

$$
\begin{array}{lll}
3 & 9 & 0.439
\end{array}
$$

Stimulus-and-

response $n s$

propositions

$\begin{array}{lllllll}\text { yes } & 14 & 66 & 0.696 & {[0.286,1.110]} & .414 & n s \\ \text { no } & 32 & 257 & 0.396 & {[0.235,0.558]} & .306 & \text { ref }\end{array}$

Perspective ns

Internal $28 \quad 175 \quad 0.42$

$[0.251,0.605]$ ref

External $\begin{array}{lll}5 & 42 & 0.205\end{array}$

Internal and External $\begin{array}{lll}3 & 65 & 0.392\end{array}$ Individual $7 \quad 48$ $48 \quad 0.479$ $[-0.114,1.070] \quad .398$ ns

Athlete characteristics

Age cont. $40 \quad 281$ $n s$

Age group $n s$

Children and Adolescents (7-18) $\begin{array}{lll}15 & 128 & 0.577\end{array}$ $[0.313,0.840] \quad \begin{array}{cc}0.26 \\ 0\end{array}$ $n s$

Adults (18 and older) $39 \quad 267$

0.412 $[0.252,0.572]$

0.31

ref

Mixed

$\begin{array}{lll}2 & 6 & -0.083\end{array}$

Sports Expertise

ns

$\begin{array}{lccccccc}\text { Novice } & 26 & 204 & 0.268 & {[0.155,0.580]} & 0.32 & 2 & \text { ref } \\ \text { Recreational } & 10 & 69 & 0.552 & {[0.299,0.806]} & 0.20 & 7 \\ & & & & & n s \\ \text { Competitive } & 10 & 81 & 0.555 & {[0.185,0.926]} & 0.39 & 0 \\ \text { Professional } & 9 & 31 & 0.390 & {[0.030,0.751]} & 0.23 & n s \\ \text { Various } & & & & - & - & - & \\ & 3 & 16 & - & - & -\end{array}$

Previous imagery experience 
Yes

No

Imagery ability

Low to moderate $\quad 2 \quad 4 \quad .118$

$\left.\begin{array}{llllll}\text { Moderate to High } \quad 12 & 64 & 0.928 & {[0.551,1.310}\end{array}\right]$

Note. - - insufficient number of data points for the analysis, ref - reference category. $n s$ - not significant, $* p<.05, * *, * p<.05$. Moderators without levels were used as continuous predictors in meta-regressions; all moderators with only one study were omitted from this table. 


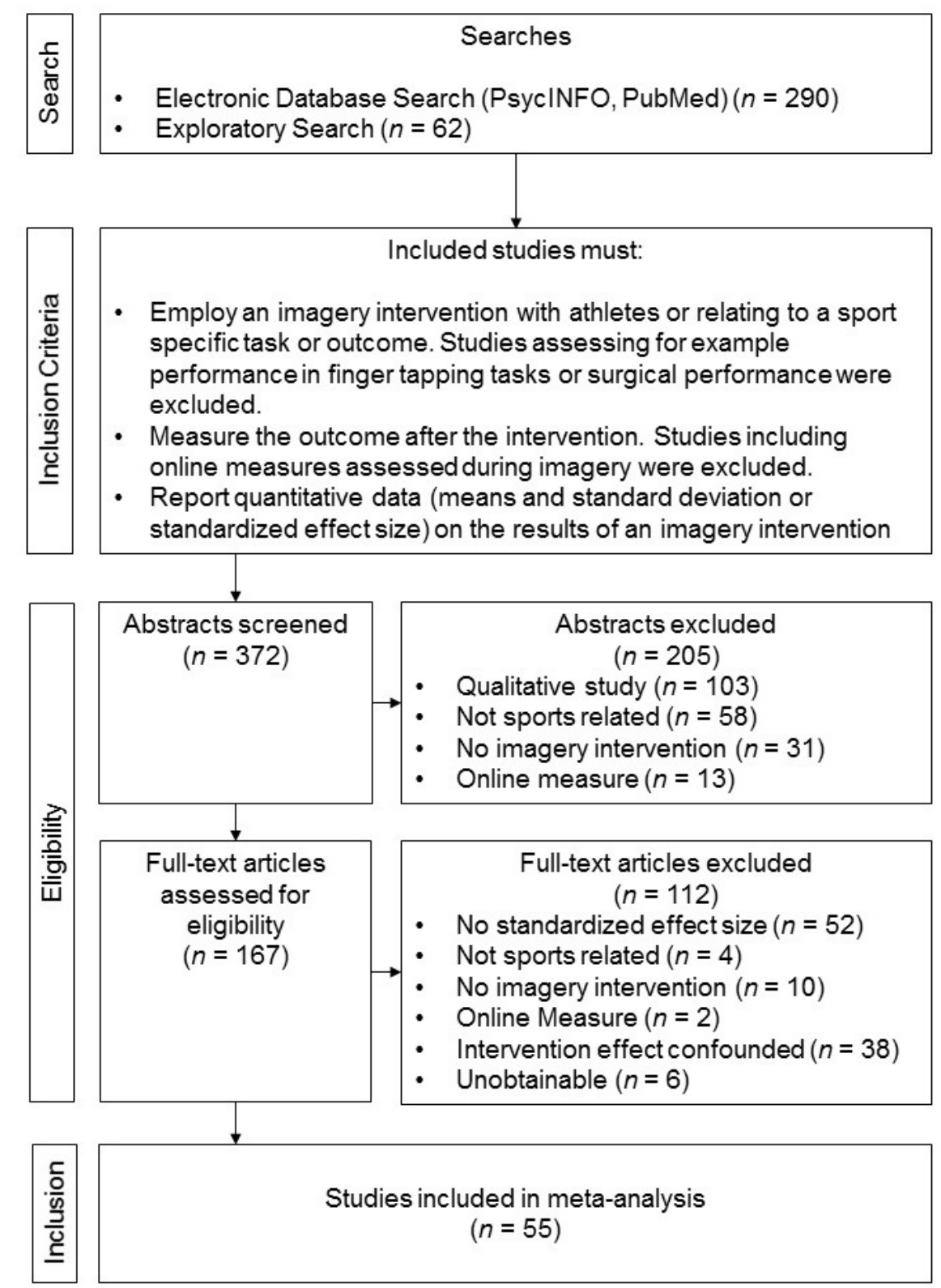

Figure 1. Flow chart of the literature search. 
Effect Size Level

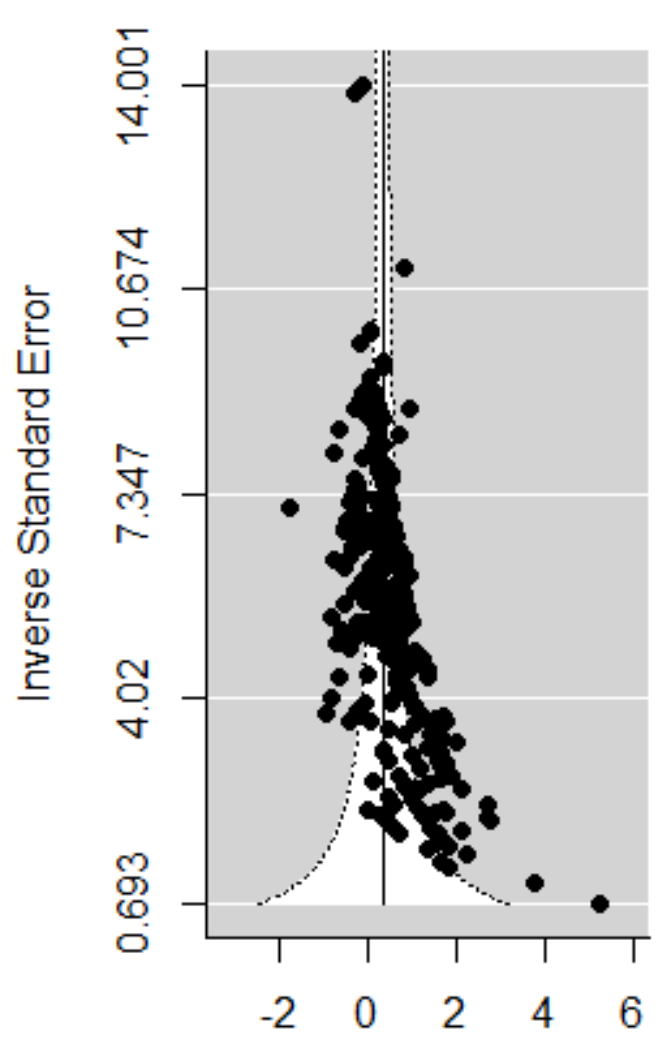

Cohens d

\section{Study Level}

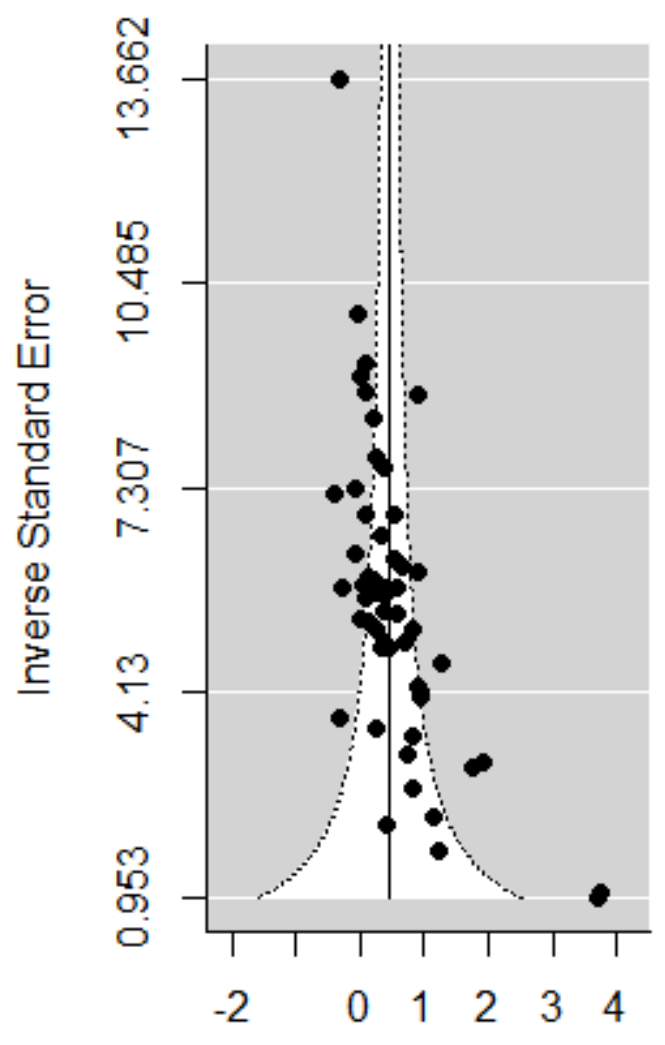

Cohens d

Figure 2. Funnel plots of the inverse standard error and the effect size Cohens's $d$ for the effect size level (left) and the study level (right). 